PART 2 

CHAPTER 4

\title{
Cultural Life Reconfigured: From the Ancestral to the Digital Commons and Beyond
}

\author{
Nicholas Anastasopoulos
}

\section{Transitioning to the digital universe}

The advent of the internet was undoubtedly the milestone of the information era, triggering a chain reaction and setting the stage for a series of revolutions in communication, production and the creative fields of culture, which characterise the period we live in. By its very nature and its operational structure of a loose, highly complex non-hierarchical network, as well as its decentralized management, the internet possesses attributes which justify its classification as a man-made common resource on a planetary scale. Virtually unlimited access to knowledge, information, opportunities for collaboration, communication, sharing, and distributed production, have all heralded the era of a digital commonwealth and of a networked public sphere (Benkler 2007).

The fact that whatever can be produced can just as easily be multiplied, distributed and shared, generated a climate of accessibility and openness. Consequently, this has led to an unprecedented social production, to a transformation of processes of collaboration and exchange, and to a movement of theorists and practitioners advocating the management of information as a digital

How to cite this book chapter:

Anastasopoulos, N. 2020. Cultural Life Reconfigured: From the Ancestral to the Digital

Commons and Beyond. In Lekakis, S. (ed.) Cultural Heritage in the Realm of the

Commons: Conversations on the Case of Greece. Pp. 97-108. London: Ubiquity

Press. DOI: https://doi.org/10.5334/bcj.f. License: CC-BY 
commons freely accessible to everyone. In this context, open-source software, creative commons, crowdfunding and Wikipedia were born, all of which are concepts that have been shaping a new environment that emerges from a rethink of issues such as copyright, licensing, and consumer and creator relationships.

\section{From the ancestral to the digital commons: Cooperate or Corporate ${ }^{24}$}

According to Yochai Benkler, "culture, shared meaning, and symbols are how we construct our views of life across a wide range of domains - personal, political, and social" (Benkler 2007: 274). Culture encompasses the behaviour, norms and expression of societies and should be understood in its widest possible definition, as forming part of a dynamic and ongoing body of creation in many fields of human activity. Cultural heritage and natural heritage domains are often indistinguishable and historically were bound together. ${ }^{25}$ Every aspect of the human condition may therefore be viewed through the cultural lens. For a community, or a nation their natural and cultural heritage remain their most vital common resources, and therefore cultural heritage should be understood as a right, as well as a common resource. Communication, expression and creativity are the components par excellence of both culture and cultural heritage, and the digital sphere currently addresses these aspects of human activity to unprecedented degrees of quantity, efficiency, speed and universality.

The commons in various forms and commoning as a practice, form a significant, uninterrupted and inextricable element of traditional and historical or indigenous populations and cultural heritage in several countries. A considerable body of knowledge concerning cultural heritage, the commons and the implication of the digital age, forms part of an entirely different cosmovision, outside of the sphere of influence of the West and the Global North (not excluding European traditions), which is worth both citing and learning from..$^{26}$ This body of knowledge has an archetypical identity and may be found in small communities everywhere. In most such communities the commons remain

${ }^{24}$ The title, implying a fundamental dilemma for the present and the future of civilization, was borrowed from the "Jamm'Art" session that Culture Action Europe (CAE) launched on July 4, 2017 addressing a European audience in the form of an online live debate. See http://jammart.eu/discussions/cooperate -or-corporate/. Last access 20 November 2019

${ }^{25}$ In that respect, institutions or entities such as UNESCO, or the Environmental Justice Atlas represent either official or activist digital portals, relating to one of the two, or both. See https://whc.unesco.org \& https://ejatlas .org/. Last access 20 November 2019

${ }^{26}$ Also often referred to as Traditional Ecological Knowledge (TEK). 
alive as a way of life in the traditions, practices, and the built environment. The rural traditions of festivals, carnivals and panigyria ${ }^{27}$ in southern Europe, and the shamanic ceremonies in the Andean communities for example, can be thought of as ancestral commons. They all provide a space and a context for people to congregate and to partake in a communal experience which they help co-create and in which they also become participants.

As we experience new enclosures, and various categories and examples of commons are being threatened with extinction, we may observe how simultaneously processes of creating new commons unfold. To a certain extent, the process of sharing today has migrated to the digital sphere, onto social networking sites and for most people the reproduction of digital content has already been a daily routine for many years. The peer-to-peer culture (P2P) is a phenomenon of commoning in the digital realm. Many citizens may produce, distribute and consume at the same time, motivated by the passion and the need for creation, communication, learning, self-realization and self-integrity, i.e. superior positive motives free from the neoliberal doctrine of the market economy that measures each resource solely through the logic of profit (Kostakis \& Bauwens 2014). However, the vast majority of users arguably perform mundane, socially or personally driven acts with such incentives as acquiring immaterial goods that previously constituted market products of high commercial value. In this sense, it can be argued that both peer to peer culture and community movements have become second nature and that as a result they are apolitical, perhaps even amoral, since they derive from all parts of the political spectrum, from the far left to the far right. A majority with no political identity, such as those internet and social media users who have developed daily routines of sharing selfies, news and other innocuous content, may be doing so without considering the ethics, morality or the ecological footprint of their actions, or perhaps in their absence altogether.

Meanwhile, the immaterial production that the internet implicitly or explicitly favours forms a new landscape of conflicts and negotiations, because it has been used as the arena for generating both surplus market value, as well as for the production of new commons. Under protocols such as open-source and creative commons, individuals and initiatives offer the fruits of their labour to a common effort, a common pool of resources or a joint project. The terms 'opensource' and 'creative commons' describe practices that promote access to the components of a digital product for its reuse, as well as for the production and development of new products. The basic operational principles and widespread

27 Term used in Greece to describe popular traditional festivities taking place in villages all over the country, usually on the occasion of a saint's name day, in which people congregate to socialize, share, and enjoy food, music and dance. These events are usually produced by the people themselves on a rotating basis. 
practices are those of a horizontal relationship arising from the exchange of information and cooperation so that the final product, the code and layout of the structure itself, as well as their documentation, remain open. Some believe it is a philosophy, while others see it as the natural evolution of the concurrent and distributed access to production, use and modification, as opposed to the centrally controlled industrial production models commonly used in commercial software companies.

In this state of affairs, much appears to be offered in the digital sphere for free, while value is created in a variety of alternative ways, such as entering a moneyless agreement with Facebook in which the central, yet unseen part of the deal involves selling the users' personal profiles to commercial, for-profit entities. In this case, should giant enterprises such as Airbnb, Amazon or Facebook be understood as corrupting, co-opting, or facilitating the principles of a sharing economy and peer to peer culture? In a recent mutation of capitalism, referred to as 'platform capitalism', the new practices of flexible forms of work producing value over digital services have profound and largely unintended side effects, both positive and negative. Consequently, in the digital era of globalized capital, overcoming the obstacles enforced by national borders can serve primarily a neo-liberal agenda and secondarily socially radical practices (Delfanti 2018; Langley \& Leyshon 2017). Nonetheless, the dog-eat-dog approach of doing anything it takes to be successful, to the detriment of others, seems to contradict some of the innate characteristics of the digital sphere and a habit, if not a culture, of sharing is undeniably on the rise. ${ }^{28}$

Wikipedia, which represents a collectively produced and managed repository of accumulated human knowledge, across languages and territories, may be thought of as the quintessential, universal digital commons. Similarly the Human Genome Project, the world's largest collaborative biological project (1990-2003) could be viewed as both a scientific, as well as a cultural achievement and therefore, cultural heritage of humanity thereafter (Bryant et al. 2007). These considerations, as well as other complicated legal issues of licensing, reproduction and use have been brought to the forefront of the debate over digital commons and to a great extent may be credited with the revival of the current widespread interest by the general public in the digital commons.

All over the world initiatives at various scales and societal levels attempting to highlight, research, expand and redefine our understanding of the commons abound, several of which involve cultural practices bridging the digital and the

${ }^{28}$ Some noteworthy examples have been developing in several countries over the last two decades under different circumstances. Since 2009, in Greece and in Spain, among many other countries, a wave of initiatives and processes have sprung as a way of mitigating the effects of the crisis, by experimenting with alternative currencies, time banks, and other forms of exchange, cooperation, commoning practices and cooperative economy. 
physical sphere. It is a challenge to delineate digital commons and the cultural heritage field as clearly defined areas, nevertheless some examples serve as references to develop a sense of the inquiry and practices pointing in this direction.

\section{Reviewing European and Latin American case studies}

Some noteworthy or emblematic European and Latin American examples that I have experienced or worked with follow, serving to map aspects of interaction and cross-over between the areas of digital commons and cultural heritage.

Several European initiatives form part of a commons-oriented shift in the collective imagination, many functioning with both strong physical and digital presence, while also belonging to wider networks forming extensive rhizomatic evolution, support and empowerment systems. These include the 'Transition Movement' and the 'Transition Towns', which originated in Kinsale, Ireland (2005), then migrated to Totnes, UK, and subsequently to several other cities in Europe and worldwide. ${ }^{29}$

The French/Romanian Atelier d'Architecture Autogérée (AAA) and the Ecuadorian Al Borde collective of architects employ parallel tactics. They both attempt to address the traditional limitations of the architect's role in responding to the true needs of communities by bypassing the restrictions of the monetary economy, 'hacking' the chain of production, and actively seeking to engage with the communities that they see as the rightful recipients of their skills. ${ }^{30}$ This is made possible through a combination of frugal living, pooled resources and the collective's reliance on the support of their digital networks and involvement in international events, which allow sustenance and transfer of monetary resources to their projects. Both of these emblematic case studies point to an updated interpretation of culture, community, the economy and the commons in a digital context.

A number of notable Italian case studies, on a municipal level, address aspects of cultural heritage as commons and experiment with cultural heritage management in a cooperative economy context. Bologna is a pioneering city with a strong tradition in the urban commons among other things, which has taken active steps towards the safeguarding of its cultural heritage, as well as of its public spaces as urban commons. ${ }^{31}$ Similarly, the city of Ghent in Belgium has

${ }^{29}$ See https://transitionnetwork.org and https://en.wikipedia.org/wiki /Transition_town. Last access 20 November 2019.

${ }^{30}$ See www.albordearq.com and http://www.urbantactics.org/. Last access 20 November 2019.

31 See http://labgov.city/thecommonspost/bologna-as-a-laboratory-for-urban -commons-urban-change-talk-berlin/. Last access 20 November 2019. 
recently taken steps at an institutional level to highlight and reinforce already existing community, heritage and commons characteristics. ${ }^{32}$

In the area of a cooperative economy, CoopCulture is the largest cooperative enterprise in the sector of cultural heritage and activities in Italy, managing the consortium of the largest museums in the country and offering a sophisticated bundle of digital services. ${ }^{33}$

\section{Greek case studies}

During the crisis years (2009 to the present) resistance and activism in Greece have often been rooted in both cultural affairs and cultural heritage. A plethora of websites, blogs end portals representing commoning activities was documented in 2014, but many have withered, disappeared, or become inactive since then. Some noteworthy cases that are still active include the Navarinou Park case, and the Embros Theater (Anastasopoulos 2012; 2014). The Victoria Square project on the other hand represents a much younger contender, coming from an entirely different perspective, i.e. the cross-over of an arts institution such as Documenta 14 and the artistic practice of the artist Rick Lowe. It is defined by its initiator as a "social sculpture", resembling a grassroots community empowerment movement based on creativity and cultural production. ${ }^{34}$

The Unmonastery is an experimental collective of young, highly skilled, and well educated people from various parts of the world, disillusioned by their efforts to make a meaningful and satisfying living by offering the fruits of their expertise to society. ${ }^{35}$ In their own words, "When it comes to work, it is increasingly difficult to reconcile making money with making sense. People work to make a living. Others work to make meaning. But the two 'works are not the same work". The initiative's principles and goals have been attempting to dissect the operating

32 At an institutional level it appears that several forward-thinking European organizations have been recently shifting their attention to the commons, cooperative forms of economy and production, etc. See for example, Culture Action Europe, and the European Commons Assembly.

33 The company was founded in January 2010 by the merger of two highly specialized companies with over 15 years of experience alongside public and private bodies, with the aim of improving the quality and variety of user services and enhancement at prestigious museums, monuments and libraries of many Italian regions. See Coopculture/Societá Cooperativa Culture: https://www.coopculture.it/. Last access 20 November 2019.

${ }^{34}$ See victoriasquareproject.gr/ and https://www.documenta14.de/en/artists /13512/rick-lowe. Last access 20 November 2019.

35 The Unmonastery initiative came into being as an initiative on the occasion of Matera awarded the Cultural Capital of Europe (CCoE) title for 2019. https://www.matera-basilicata2019.it/it/. Last access 20 November 2019. 
principles, signs and contradictions of our times, seeking to match highly skilled and intelligent individuals possessing a strong sense of ethics, with communities, thus addressing the harsh circumstances imposed on both communities and individuals by the neoliberal economy. Digital culture and open source forms a significant part in their principles and practices, both in the members' expertise, communication, and interface with other communities. ${ }^{36}$

\section{The Ecuadorian experiment}

Ecuador is a South American country whose territory encompasses a substantial percentage of the Amazon, the forest with the richest biodiversity on Earth, and it represents an outstanding example. Its natural wealth has been managed by the indigenous communities that have been living there for millennia through accumulated wisdom, the result of producing empirical knowledge through the trial and error of its peoples. The concept of Sumak Kawsay, best described as Life in Harmony, embodies the very essence of this cultural heritage and the commons, and it encapsulates the belief that humans form part of the ecosystem and do not stand apart from it. ${ }^{37}$

The FLOK Society (Free, Libre, Open Knowledge Society) Project was greatly publicized and appeared as the flagship research project with the task of laying the foundations of a new approach to knowledge and its role in a knowledgebased orientation for the future of the economy of the country. ${ }^{38}$ The FLOK

36 The Unmonastery group has had an "Athenian phase", and engagement with the city between 2015 and 2016, as well as an ongoing Greek phase and a remote community of Kokkinopylos on Mount Olympus. See http:// unmonastery.org. Last access 20 November 2019.

${ }^{37}$ In 2008 Ecuador was the first nation to vote and put in effect a constitution which acknowledges Rights to Nature. Despite the somewhat poor results, the significance of the precedence of the Ecuadorian Constitution remains, and it has been inspiring ever since in nations such as Bolivia, activists and individuals, setting new standards. These ideas were first adopted at state level and appropriated in the better-known 'Buen Vivir principles', but the relationship between the original holders of this heritage and knowledge, its indigenous populations and the state remains tense and unresolved. Nina Pacari, a representative of the indigenous movement, claims that there is a new academic, state and financial hegemony being established in the name of its peoples' cultural heritage, in their absence, or often in their detriment.

38 The FLOK society project was a research project aiming to formulate proposals to the Ecuadorian government for policy making in various sectors of the economy and human activity, with the goal of achieving economic, as well as social and ecological emancipation through distributed, knowledge production in the context of a digital environment and economy. The work 
Society Project drew inspiration and reference from the indigenous communities of Ecuador and the practice of 'minga', in an attempt to instil it in the sphere of the digital world and technology. The proposals that have emerged concern education, science and culture as well as open source manufacturing and distributed energy production, based on examples from the international sphere (Vila-Viñas et al., 2015). It is not yet known how and in what circumstances the suggestions will apply, and there is much to be debated about this venture that has caused a great deal of agitation among the commoners and scholars worldwide, acting thereafter as a reference and a catalyst for the future, in terms of developments in the digital community.

\section{Challenges around the commons and P2P Ethics}

The digital sphere tends to breed illusions of universality generated by a global culture, ease and speed of dissemination of information. Naturally, all of these come into sharp contrast with the diverse lifestyles, production and consumption patterns that form part of the cultural heritage of different regions and the cultural origins of individualities and collectivities that are associated with local characteristics, as well as with specific moments of history. Several gaps and contradictions arise, given that precarity and the inequalities and difficulties in the material world seem to persist and expand rather than diminish. Despite the fact that we interact, coexist, share content and develop common areas beyond national and other boundaries more than ever, we are far from overcoming the barriers stemming from cultural disparities, economic inequalities and geopolitical interests. In the context of a neoliberal global economy, a common cultural heritage is more vulnerable than ever and runs the risk of being eroded, appropriated, privatized or eradicated altogether. Profound transformations in production which gradually coincide with the loss of control and sovereignty over resources, force and coerce people to sacrifice their cultural heritage to the market, in exchange for survival. ${ }^{39}$

Each era is characterized by a set of beliefs, rules, and codes of conduct that are referred to as ethics, but as was explained above, the current period is a transitional one. Therefore, as our time possesses transitional characteristics,

\footnotetext{
of the research group was coordinated by Michel Bauwens and took place between September 2013 and June 2014.

${ }^{39}$ In China, state and neoliberal predatory tactics have massively been destroying, in a matter of years, century-old traditions of siheyuan and hutong (traditional residences and alleys) replacing them with monstrous megacities. In Athens a state alliance with corporate multinational interests has had no qualms over selling out a cultural heritage site of global proportions such as Plato's Academy to real estate development for a Shopping Mall, which would coopt the site's name to that of Academy Gardens (See Galanos, this volume).
} 
until a new modus operandi is established and becomes universally accepted, we will continue living in a precarious, conflictual and experimental state of affairs of ambiguous ethics. At the beginning of the twentieth century, German philosopher Max Weber wrote an essay titled Protestant Ethics and the Spirit of Capitalism. Protestant ethics stemmed from northern Europe, where work was considered an end in itself (the means to avoid inertia, which can lead to sin) and a goal in which the entrusted task must be completed regardless of its value (Furnham 1984). Weber argued that modern bureaucratic capitalism was born out of the confirmation of this Protestant morality of work. In an attempt to map developments in immaterial peer production, Finnish philosopher Pekka Himanen more recently introduced the ethics for the work of hackers (2010). According to Himanen, work must be interesting, entertaining and, above all, it must create value for the worker, the organization and society as a whole. Workers must also have the freedom to organize their work in a more functional way and reach their goals in the way that best suits their needs and ideas (Himanen 2010; Weber et al. 2002).

While ethics in general have been significantly challenged or undermined, one key characteristic of the new era is the emergence of social relations based on a 'commons ethics'. New practices attempt to return to the physical and material environment focusing on resource management and their use at various levels, such as nutritional, spatial, cultural and urban, and most significantly ethical. In these developments we find new attitudes towards ideology and morality, which help shape new political theories and ideas beyond capitalism, even a new meaning for existence. The ethics of the commons permeating mostly unwritten cultural structures and defining rules of conduct, stem from fundamental aspects of the human condition, which have traditionally been characterized by qualities of cooperation and sharing (Costanza-Chock et al. 2018). These ethics embody the concept of commoning, a term that describes the practices of collective creation and active management of the commons. Both traditional and modern communities are the expression of commoning activity and some forms of cooperative economies may be seen as the expression of this common ethics and commoning in practice (Bollier 2014: 147).

\section{Conclusions or, what is at stake?}

As with many other technological advances, digital culture remains a doubleedged sword. In this respect we observe digital activities that may be classified as commoning activities surviving in the midst of an ocean of predatory actors in the digital sphere. The appropriate national as well as international legal context required in order to support such enterprises and to safeguard it from the risks of perishing or being privatised, is missing. Societies are experiencing recurring cases of enclosure and subsumption of their cultural heritage by neoliberal processes in which the nation-state serves primarily as the agent for 
this transaction. Despite differences, the same challenges and similar victories and defeats seem to be the case for both European and Latin American case studies.

On the antipode of the commons, citizen initiatives, grassroots culture, Keller Easterling researches and analyses the mechanisms of capital in the digital era (Easterling 2014) and speaks of the complex infrastructure of a global scale that has been put into place in order to facilitate the flaw of capital beyond national laws, local conditions and regional restrictions. She likens the present condition to a David vs Goliath case, which despite the apparently insurmountable difficulties leaves us with the hope that, as the fable goes, and as several of the case studies discussed allow us to hope, size and might do not always determine the outcome.

Where shall we start? Fostering a genuine commons and peer-to-peer ethics climate, through education and the social, political, and legal infrastructure seems to be a safe and sustainable way forward.

\section{Bibliography}

Anastasopoulos, N. (2012). Share! In P. Dragonas \& A. Skiada (Eds.), Made in Athens. $13^{\text {th }}$ international architecture exhibition. La Biennale di Venezia (pp. 91-99). Athens, Greece: Ministry of Environment, Energy and Climate Change \& Authors.

Anastasopoulos, N. (2014). The rise of communitarianism and other alternative movements from the Athenian crises. In E. Russell \& P. Gallardo (Eds.), Yesterday's tomorrows on utopia and dystopia (p. 217-226). Newcastle upon Tyne, United Kingdom: Cambridge Scholars Publishing.

Barandiaran, X. E., Vila-Viñas, D. \& Vázquez, D. (2015). Buen Conocer/FLOK Society como proceso de investigación colaborativa y diseño participativo. In Vila-Viñas, D. \& Barandiaran, X. E. (Eds.), Buen Conocer/FLOK Society: Modelos sostenibles y políticas públicas para una economía social del conocimiento común y abierto en el Ecuador (pp. 7-58). Quito, Ecuador: IAEN-CIESPAL. Retrieved August 21, 2018, from http://book.floksociety .org/ec/0/0-2-metodologia-arquitectura-de-la-participacion-durante-el -proceso-flok/.

Benkler, Y. (2006). The wealth of networks: How social production transforms markets and freedom. New Haven, CT: Yale University Press.

Bollier, D. (2014). Think like a commoner: A short introduction to the life of the commons. Gabriola Island, BC: New Society.

Bryant, J. A., Collins, M. W. \& Atherton, M. A. (2007). Design and information in biology: From molecules to systems. Southampton, United Kingdom: WIT Press.

Costanza-Chock, S., Wagoner, M., Taye, B., Rivas, C., Schweidler, C., Bullen, G. \& the T4SJ Project. (2018). \#MoreThanCode: Practitioners reimagine the 
landscape of technology for justice and equity. Research Action Design \& Open Technology Institute. Retrieved August 21, 2018, from https:// morethancode.cc/T4SJ_fullreport_082018_AY_web.pdf.

Delfanti, A. (2018, August 16). Amazon is the new FIAT. The worker and the union, 3. Retrieved August 21, 2018, from http://notesfrombelow.org /article/amazon-is-the-new-fiat.

Easterling, K. (2014). Extrastatecraft: The power of infrastructure space. Brooklyn, NY: Verso.

Furnham, A. (1984). The protestant work ethic: A review of the psychological literature. European Journal of Social Psychology, 14 (1), 87-104. DOI: https://doi.org/10.1002/ejsp.2420140108.

Hardt, M. \& Negri, A. (2011). Commonwealth. Cambridge, MA: Belknap Press.

Himanen, P. (2010). The hacker ethic: A radical approach to the philosophy of business. New York, NY: Random House.

Kostakis, V. \& Bauwens, M. (2014). Network society and future scenarios for a collaborative economy. London, United Kingdom: Palgrave Pivot.

Langley, P. \& Leyshon, A. (2017). Platform Capitalism: The intermediation and capitalization of digital economic circulation. Finance and Society, 3(1), 11-31. DOI: https://doi.org/10.2218/finsoc.v3i1.1936.

Virno, P. (2008, June 22). A grammar of the multitude: For an analysis of contemporary forms of life. Retrieved August 28, 2018, from https://web .archive.org/web/20080622073210/http://www.generation-online.org/c /fcmultitude3.htm.

Weber, M., Baehr, P. \& Wells, G. C. (2002). The protestant ethic and the spirit of capitalism: And other writings. New York, NY: Penguin Classics. 
